\title{
Predicting Job Burnout, Based on the Quality of Marital Relationship and Sexual Dysfunction in Tehran Firefighters

\author{
${ }^{* 1}$ Dr.Effat Merghati-Khoei, ${ }^{2}$ Asila Hajian Motlagh \\ ${ }^{2}$ MSc, Department of Psychology, Garmsar Islamic Azad University, Iran. \\ *Email: motlagh125@gmail.com
} \\ ${ }^{* 1} \mathrm{PhD}$. Associated Professor. Department of Medical Science, University of Tehran, Iran.
}

Received: 10 ${ }^{\text {th }}$ December 2017, Accepted: 8th February 2018, Published: 28th February 2018

\begin{abstract}
Introduction: Sexual dysfunction is a factor that is associated with job burnout. Sexual dysfunction can affect the quality of life of millions of men and their sexual partners and most of them prefer to suffer in silence. The aim of this study was to predict job burnout on the quality of the marital relationship and sexual dysfunction. Method: This study was conducted by using descriptive-correlation method. 300 Firefighters in the city of Tehran were selected by using convenient sampling method and they completed Maslach burnout inventory (1981); ENRICH marital satisfaction inventory (1989) and erectile function index (1997). Results: Findings showed that there is a significant relationship between the quality of marital relationship and sexual dysfunction. Also simultaneous regression analysis showed that the quality of marital relationship and sexual dysfunction predicts about $15.5 \%$ of the variance of job burnout in firefighters. Conclusion: Fire department personnel are facing tens and distressful job. Their 24-hour work schedule which somehow imbalances their biological clock, all of these factors decrease the quality of their marital relationship and lead to sexual problems such as erectile dysfunction and all of them create a high rate of job burnout in fire department personnel.
\end{abstract}

Keywords: Job Burnout, Quality of Marital Relationship, Sexual Dysfunction

\section{Introduction}

Firefighters confront difficult and stressful takes. These people are always on standby and encounter the accident and unexpected events and situations. In most of these cases, things get out of control and a large number of firefighters around the world lose their lives every year. Firefighters and workers who work as a team in comparison to those who work independently are more together at the time of performing their tasks and their work relationships can have a huge impact on them (Bakker, Demerouti, \& Verbeke, 2004). High risk and sensitivity, complex and uncertain working conditions, direct exposure to a variety of accidents and harmful agents, shift work and the need for staff preparation at any hour of the day and night have all resulted in classification of firefighting as a hard and harmful job. Significant more level of stress
(Darvishi, et al., 2015) and decreased job satisfaction in these individuals (Darvishi, et al., 2015). Studies have shown that high pressure and stress is one of the major causes of job burnout (Pardakhtchi et al; 2009).

The human environment includes physical, social and psychological factors and all of them affect the status of job burnout. One of the fatigue-causing factors in humans is the workplace which can also affect other areas of life (Bass and Jonson 1994). One concept that has attracted the attention of occupational, productivity, industrial and organizational psychologists, in recent years is job burnout and its symptoms, causes and it is adverse impacts. It seems that job burnout is related with psychological, physical and social pressures and the effects of constant psychological pressure is more prominent in this issue and it has been shown that job burnout occurs as a result of constant psychological pressure. Job burnout is affected by various factors such as type of job, conflict and confusion in the role, excessive working pressure, type of management, lack of social support, organizational change and changing working hours (Fletcher, 2001).

The World Health Organization defines sexual health as integrity and harmony between mind emotions and body which pushes social and intellectual aspects of human toward development of his personality and results in relationship and love (WHO). Therefore, any disorder leading to inconsistency and a lack of satisfaction with sex, can cause sexual dysfunction (Jahanfar and Molaei nezhad, 2001). Therefore, any disorder leading to disharmony and dissatisfaction of sexual relationship can entail sexual dysfunction (Mousavi et al; 2013). Researchers have also warned about the impact of sexual dysfunction on marital well-being (McCarthy, 2003) and sexual dysfunction is one of the factors associated with job burnout (Laumann, Paik, \& Rosen, 1999) and given the strong connection between sexual dysfunction and quality of life, it can play an important role in the diagnosis of mental health status (Laumann et al., 1999). Briefly, studies have shown that there is a relationship between the quality of marital relationship and job burnout). Studies have also shown that there is a relationship between sexual dysfunction and job burnout (Arizi et al., 2015). This 
research aims to answer these questions: 1 . Is there a relationship between the quality of marital relationship and job burnout in firefighters? 2. Is there a relationship between sexual dysfunction and job burnout? 3. And how much sexual dysfunction is predictive value for job burnout, based on the relationship between marital relationship and sexual dysfunction in firefighters? The study is correlation has two objectives: 1- Determining the relationship between variables. 2- Prediction of a variable based on other variable. In this study both of the objectives are considered.

\section{Methodology}

In this descriptive and correlation research we recruited 300 firefighters working ate fire station across the city of Tehran. For data collection, we used convenience sampling method by referring to the Krejcie and Morgan table (1953).

After conducting required arrangements with the authorities of fire stations across Tehran and explaining the research to them, all of those who were willing to cooperate were invited. After interviewing with each of these individuals and explaining the principle of confidentiality we recruited those who are married and male firefighters and they are working in the operating fire department and live in Tehran. Their average age is 57/34. Among of these 300 firefighters, 103 people are in the age range 29-22 years old, 94 people are in the age range $37-30$ years, 57 people are in the age range 44-38 years old, 46 people are in the age range 52-45 years. Most people are of a Bachelor's degree and minimum Firefighters are diplomas. Geldard job burnout inventory; ENRICH marital satisfaction inventory and International index of erectile function.

To analyze the data, descriptive and inferential statistical methods were used. Mean and standard deviation were used in descriptive statistics section and in inferential statistics section, Pearson correlation coefficient was used to determine the relationship between different variables and simultaneous multiple regression was used to predict one variable based on other variables.

\section{Results and Discussion}

We found a significant adverse, relationship between a quality of marital relationship and job burnout in firefighters $(\mathrm{P}<0 / 01 ; \mathrm{r}=-0 / 253)$ at the 0.01 level. In other words, by increasing the quality of marital relationship, job burnout in firefighters decreases and vice versa (Table 1).

Table 1. Mean Standard Deviation and Correlation Coefficient

\begin{tabular}{|l|l|l|l|l|}
\hline Variable & MD & SD & The Quality of Marital Relationship & Job Burnout \\
\hline The Quality of Marital Relationship & $3 / 549$ & $0 / 529$ & 1 & \\
\hline Job Burnout & $2 / 553$ & $0 / 397$ & $-0 / 253$ & 1 \\
\hline
\end{tabular}

Significant negative relationship was found between sexual dysfunction and job burnout in firefighters $(\mathrm{P}<0 / 01$; $\mathrm{r}=0 / 247$ ) at the $0 / 01$ level (Table 2).

Table 2. Mean Standard Deviation and Correlation Coefficient

\begin{tabular}{|l|l|l|l|l|}
\hline Variable & MD & SD & Sexual Dysfunction & Job Burnout \\
\hline Sexual Dysfunction & $3 / 177$ & $0 / 406$ & 1 & \\
\hline Job Burnout & $2 / 553$ & $0 / 397$ & $0 / 274$ & 1 \\
\hline
\end{tabular}

According to the results the quality of marital relationship was not associated with sexual dysfunction in firefighters (Table 3).

Table 3. Mean Standard Deviation and Correlation Coefficient

\begin{tabular}{|l|l|l|l|l|}
\hline Variable & MD & SD & $\begin{array}{l}\text { The Quality of Marital } \\
\text { Relationship }\end{array}$ & Sexual Dysfunction \\
\hline The Quality of Marital Relationship & $3 / 54$ & $5 / 29$ & 1 & \\
\hline Sexual Dysfunction & $3 / 177$ & $0 / 406$ & & 1 \\
\hline
\end{tabular}

Based on the results, the predictor variables can predict criterion variables $(P \leq 0: F=27 / 217)$. In other words, the quality of marital relationship and sexual dysfunction can predict job burnout in firefighters (Table 4).

Table 4. The Results of Variance Analysis of Job Burnout based on the Predictor Variables

\begin{tabular}{|l|l|l|l|l|l|}
\hline Sources of Changes & Sum of Squares & df & Sig & Mean Squared & F \\
\hline Regression & $7 / 328$ & 2 & $0 / 0005$ & $3 / 664$ & $27 / 217$ \\
\hline Remainder & $39 / 983$ & 297 & & $1 / 35$ & \\
\hline Total & $47 / 312$ & 299 & & & \\
\hline
\end{tabular}

According to the value of R2, we can conclude that quality of marital relationship and sexual dysfunction presented in the model explain about $15.5 \%$ of job burnout in firefighters totally (Table 5). 
Table 5. The Summary of Regression Analysis of Job Burnout by using Simultaneous Model

\begin{tabular}{|l|l|l|l|l|l|}
\hline Model & Variable & $\mathrm{R}$ & $\mathrm{R}^{2}$ & Standard $\mathrm{R}^{2}$ & Error \\
\hline 1 & The Quality of Marital Relationship Sexual Dysfunction & $0 / 394$ & $0 / 155$ & $0 / 149$ & $0 / 3669$ \\
\hline
\end{tabular}

The amount of beta in the model represent the amount of explanation of predictor variable's variance on criterion variables. According to the standard coefficient, with on unit chance in the variance of quality of marital relationship, the variance of job burnout in firefighters will change -0.284 . Sexual dysfunction also plays a significant role in explaining job burnout and the amount of this effect is 0.303 . Also according to the standardized coefficients sexual dysfunction has a larger role in explaining job burnout compared to the variable of quality of marital relationship (Table 6).

Table 6. The Results of Regression of Job Burnout based on Predictor Variables

\begin{tabular}{|c|c|c|c|c|c|}
\hline \multirow{2}{*}{ Predictor Variables } & \multicolumn{2}{|c|}{ Non-Standardized Coefficients } & \multirow{2}{*}{$\begin{array}{l}\text { Standardized } \\
\text { Coefficients } \\
\text { Beta }\end{array}$} & \multirow{2}{*}{$\mathrm{T}$} & \multirow{2}{*}{ Sig } \\
\hline & B & $\begin{array}{l}\text { Error of Non- } \\
\text { standardized coefficients }\end{array}$ & & & \\
\hline Fixed Effect & $2 / 367$ & $0 / 209$ & & $11 / 317$ & $0 / 000$ \\
\hline The Quality of Marital Relationship & $-0 / 214$ & $0 / 040$ & $-0 / 284$ & $-5 / 300$ & $0 / 000$ \\
\hline Sexual Dysfunction & $0 / 297$ & $0 / 035$ & $0 / 303$ & $5 / 858$ & $0 / 000$ \\
\hline
\end{tabular}

In this study, mean age of the participants was 34-57 of 300. 103 Mean aged between 22-29 years old (34/34\%); 94 between $30-37$ years old $(31.33 \%) ; 57$ were between $38-44$ years old (19\%) and 46 aged between $45-52$ years old $(15.33 \%)$. In terms of education, among 300 people 21 of them had a diploma (7\%); 95 of them had an associate degree (31.67\%); 161 of them had some bachelor degrees $(53.66 \%)$ and 23 persons had a master degree $(7.67 \%)$.

In his research showed that burnout and quality of life there is a significant relationship. In other words, whatever the burnout increasing employment, quality of life is also reduce (Pardakhtchi et al, 2009). The group members have used sick leave burnout is high and one of the reasons of this group the top burnout is caused on health-related quality which includes coverage of physical and emotional well-being, cognitive function, sleep, general health, social and Performance affect sex (Grensman et al., 2016). In one research in Romania shown that the relationship between burnout, depression, anxiety and quality of life among employees in private centers Romania that there is between burnout, depression, anxiety and quality of life and its components are related (Craiovan, 2015). In one study shown that to determine the quality of life and elements of burnout on 105 trainee orthopedic Dutch did. The results showed that the quality of life and its components are associated with burnout. Such as research mentioned above, the same results were obtained for us except that we have assessed the effect of burnout on Sexual dysfunction that results have shown in all tables above.

\section{Conclusion}

In this study it was found that there is a significant negative relationship between quality of marital relationship and job burnout. In other words, by increasing the quality of marital relationship job burnout decreases and vice versa. There is a significant positive relationship between sexual dysfunction and job burnout. In other words, by increasing sexual dysfunction, Job burnout increases and vice versa. Also variables of quality of marital relationship and sexual dysfunction explained 15.5 $\%$ of job burnout totally. According to the results of the study, we can say that regarding stressful and tense conditions which fire department personnel are facing and considering that these environmental factors create severe stress and anxiety in these individuals and also regarding their 24-hour work schedule which somehow imbalances their biological clock, all of these factors decrease the quality of their marital relationship and lead to sexual problems such as erectile dysfunction and all of them create a high rate of job burnout in fire department personnel.

\section{Suggestions}

Fire department officials and authorities can reduce the rate of job burnout by improving the quality of marital relationships and by increasing their attention to sexual problems of their staff. This can increase their capabilities and morale and can provide better services as well. 


\section{References}

[1] Bakker, A. B., Demerouti, E., \& Verbeke, W. (2004). Using the job demands-resources model to predict burnout and performance. Human resource management, 43(1), 83-104. DOI: 10.1002/hrm.20004

[2] Burbeck, R., Coomber, S., Robinson, S., \& Todd, C. (2002). Occupational stress in consultants in accident and emergency medicine: a national survey of levels of stress at work. Emergency Medicine

Journal, 19(3),

$234-238$

http://dx.doi.org/10.1136/emj.19.3.234

[3] Craiovan, P. M. (2015). Burnout, depression and quality of life among the Romanian employees working in non-governmental organizations. Procedia-Social and Behavioral Sciences, 187, 234238. https://doi.org/10.1016/j.sbspro.2015.03.044

[4] Duraisingam, V., Pidd, K., \& Roche, A. M. (2009). The impact of work stress and job satisfaction on turnover intentions: A study of Australian specialist alcohol and other drug workers. Drugs: Education, prevention and policy, 16(3), 217-231.

http://dx.doi.org/10.1080/09687630902876171

[5] Fletcher, C. E. (2001). Hospital RNs' job satisfactions and dissatisfactions. Journal of Nursing Administration, 31(6), 324-331.

[6] Grensman, A., Acharya, B. D., Wändell, P., Nilsson, G., \& Werner, S. (2016). Health-related quality of life in patients with Burnout on sick leave: descriptive and comparative results from a clinical study.

[7] Laumann, E. O., Paik, A., \& Rosen, R. C. (1999). Sexual dysfunction in the United States: prevalence and predictors. Jama, 281(6), 537-544. doi:10.1001/jama.281.6.537

[8] McCarthy, B. (2003). Marital sex as it ought to be. Journal of Family Psychotherapy, 14(2), 1-12. http://dx.doi.org/10.1300/J085v14n02_01

[9] Van Vendeloo, S., Brand, P., \& Verheyen, C. (2014). Burnout and quality of life among orthopaedic trainees in a modern educational programme. Bone Joint J, 96(8), 1133-1138.

DOI: 10.1302/0301-620X.96B8.33609

[10] Darwishi, A., Sadeghi, F., Sa'edpnah, K., Darvishi, E., Sadeghi, F., \& Saed Panah, K. (2015). Investigating factors affecting occupational stress in firefighters (a cross sectional study). Health system research, 11 (1), 184-192.

[11] Pardakhtchi, Mohammad Hassan; Ahmadi, Gholamali; Dare, Farideh. (1388). A Study on the Relationship Between Quality of Work Life and Burnout among Teachers and School Teachers in Takestan. Quarterly Journal of Educational Management, Islamic Azad University, Garmsar Branch, Third Year, No. 3, Autumn 88, pp. 25-80. [12] Arizi, Mohammad Reza; Nouri, Abolghasem; Zare; Razieh; Amiri, Born. (1392). A study on the relationship between burnout and mental health. Journal of Social Welfare Research, thirteenth year, No. 48, pp. 91-11

[13] Jahanfar Shayesteh, Molaei Nejad Mitra. Sexual Dysfunction Syllabus. First Edition. Tehran, Beyeh, Nasarsalimi, 2001, pp. 11-79.

[14] Mousavi, Seyyed Qasim; Asadi Fotaby, Ahmad Ali; Houshmand; Abbas; Mehran; Abbas; Alavian; Seyyed Moeid \& Mohebi; Siamak. (1392). The Relationship between Sexual Dysfunction and Depression Level in Men with Hepatitis B. Journal of Health Systems Extensions 2013; 9 (7): 663-671 